\title{
Tulane
}

Tulane Economics Working Paper Series

\section{Middle Class Flight from Post-Katrina New Orleans: A Theoretical Analysis of Inequality and Schooling}

\author{
Stefano Barbieri \\ Department of Economics \\ Tulane University \\ sbarbier@tulane.edu
}

\author{
John H. Y. Edwards \\ Department of Economics \\ Tulane University \\ edwards@tulane.edu
}

Working Paper 1519

September 2015

\begin{abstract}
This paper stylizes the most salient characteristics of New Orleans' people and the Katrina evacuation and constructs a formal, theoretical model of their decision to return. We use the model to examine the post-Katrina population composition of the city, the evolution in its income distribution and in the welfare of its citizens, and changes in the level of education privately and publicly provided. Our results are, overall, positive for the new New Orleans. While smaller, the new New Orleans is more skill-intensive and education levels improve; these changes are broadly consistent with observed effects of Katrina on New Orleans. Moreover, while the possibility remains that Katrina-like events cause "middle-class flight," inequality is reduced under standard distributional assumptions, such as log-concavity. Nonetheless, the fact that many among the unskilled are unable to return remains problematic from an ethical point of view. Our analysis of a disaster's long term impact on a city through its effects on demographic composition, income and human capital distribution, and fiscal structure elucidates major determinants of urban resilience after a natural disaster.
\end{abstract}

Keywords: local public goods, inequality, disasters, income distribution, education, resilience JEL codes: H3, H4, I2, I3 


\title{
Middle Class Flight from Post-Katrina New Orleans: A Theoretical Analysis of Inequality and Schooling
}

\author{
Stefano Barbieri* John H. Y. Edwards ${ }^{\dagger}$
}

September 11, 2015

\begin{abstract}
This paper stylizes the most salient characteristics of New Orleans' people and the Katrina evacuation and constructs a formal, theoretical model of their decision to return. We use the model to examine the post-Katrina population composition of the city, the evolution in its income distribution and in the welfare of its citizens, and changes in the level of education privately and publicly provided. Our results are, overall, positive for the new New Orleans. While smaller, the new New Orleans is more skill-intensive and education levels improve; these changes are broadly consistent with observed effects of Katrina on New Orleans. Moreover, while the possibility remains that Katrina-like events cause "middle-class flight," inequality is reduced under standard distributional assumptions, such as log-concavity. Nonetheless, the fact that many among the unskilled are unable to return remains problematic from an ethical point of view. Our analysis of a disaster's long term impact on a city through its effects on demographic composition, income and human capital distribution, and fiscal structure elucidates major determinants of urban resilience after a natural disaster.
\end{abstract}

Keywords: Local Public Goods, Inequality, Disasters, Income Distribution, Education, Resilience JEL codes: H3, H4, I2, I3

\section{Introduction}

\subsection{New Orleans and Katrina}

We begin with an informal narrative of the immediate impact of Katrina on the city and of the long term changes it caused. We then move on to a formal treatment of urban disaster and resilience.

The complete evacuation of a major city like the one that took place in New Orleans after hurricane Katrina is unprecedented in American history. Businesses, schools, and public services shut down. Almost everybody left the city. Not only was the scope of the evacuation exceptional, its duration was too. The first people to return were men. New Orleans was a rough and dangerous place when they began straggling back in late September 2005. Entire city blocks had burned to the ground. Thugs roamed the streets. Trees and power lines were down. Stop signs and signs with street and store names had blown away. There were no working traffic lights, no open stores, no functioning gas stations. The banks were all closed and, without

\footnotetext{
*Department of Economics, Tulane University, 206 Tilton Hall, New Orleans, LA 70118; email: sbarbier@tulane.edu.

${ }^{\dagger}$ Corresponding Author. Department of Economics, Tulane University, 206 Tilton Hall, New Orleans, LA 70118; email: edwards@tulane.edu.
} 
power lines and phones, ATM machines and credit cards were useless. In the city's soft alluvial soil, broken water mains readily formed potholes big enough to rip an axle off your car. There was no electricity, no cooking gas, no cell phone service. And, if you were lucky enough to have water, it was for flushing; you did not dare drink it or bathe in it.

As the metropolitan community made up of New Orleans and the less publicized St. Bernard Parish and Slidell attempted to reconstitute itself, it became clear that the pieces no longer fit together quite the way they used to. Mayor Ray Nagin urged New Orleanians to return. Parents asked, "Return to what?" There was no place to live and no place to enroll the kids. One of the first things the city did after the hurricane was to fire all teachers. People improvised. There was the Sugarcane Academy, founded when a small group of evacuees sought refuge together in the Cajun city of Lafayette. Someone recognized two out-of-work public school teachers on the street. They got together in a sugarcane field and held classes for two months, then moved the entire operation back to New Orleans to empty classrooms on the Loyola University campus and the public school continued to operate there. There were the 5 private schools that re-opened make-shift classes in October, by combining students to fill the roster. The 7 best public schools broke off from the official system and re-opened to a diminished student body - many teachers gone - in mid-January. But the vast majority of schools did not open at all during the 2005-2006 school year. ${ }^{1}$

At least as important as the physical transformation brought about by the hurricane, looters, insurance cancellations, and human folly were the changes wrought by the collective hiatus. September 2005, the first month of federal government inaction, was very difficult. Families roamed the country by car, bus, and air. They did so in an information vacuum, not knowing if they had lost their house, their job, a loved one. They survived on the generosity of credit card companies that waived late fees and credit limits, rental car companies that didn't ask where their New Orleans cars had gone, cell phone companies that stopped charging roaming fees and forgave excess minutes. They survived on the generosity of family, friends, and complete strangers.

They also survived on the generosity of destination communities that were usually very welcoming. State and local governments, together with private organizations and individual benevolence, provided clothing, shelter, and food. Schools bent over backwards to accept "Katrina refugees" and PTAs donated backpacks and school supplies. After that first month of inaction, the administration made up with adjustment benefits that were cumbersome to obtain, but generous.

New Orleanians had experienced evacuations before. What was unprecedented about this one was that

\footnotetext{
${ }^{1}$ In the fall of 2005 there were 119 public elementary schools in operation in Orleans Parish. Then Katrina hit. In February of 2006 only 17 were open. Of these 17 open schools, only two ordinary schools operated by the local Orleans Parish School Board remained. The other 15 had been taken over by the States Recovery School District or were new charter schools that split off from the main public system (Louisiana Department of Education, 2006).
} 
everyone in the city stayed away long enough to obtain a very good picture of what it would be like to live elsewhere. $^{2}$ They found a place to live and became fully engaged in local routines like shopping, going to church or temple, and enrolling the kids in school. It often meant getting a new car, a new driver's license in another state, and a new job. A year later, more than half of the population had not returned.

Before the fall of 2005 the city of New Orleans was known for a nationally unrivaled cultural legacy of music, architecture, culinary arts, and theater. But the area was also known for having a very unequal distribution of income and one of the worst public school systems in the country. In 1999, $25.6 \%$ of New Orleans households were below the poverty line. ${ }^{3}$ Public schools were miserably bad. Out of 77 Orleans Parish public primary schools controlled by the School Board that were tested by the state in 2004, 43 were classified as having unacceptable academic performance and an additional 4 were closed altogether. Orleans Parish public schools ranked 66th out of 66 parishes in the 2003-2004 school district performance scores measured by the Louisiana Department of Education. ${ }^{4}$

Furthermore, though a majority of the population, public school families were politically disenfranchised. Only $27.9 \%$ of registered voters exercised their right in local plebiscites that would affect school financing and administration issues. ${ }^{5}$ One-third of New Orleans students attended private schools before Katrina, 3 times more than the national average. African Americans made up $65 \%$ of New Orleanians, but $94 \%$ of public school students. Citywide, $40 \%$ of children lived below the poverty line, but the proportion in public schools was $77 \%{ }^{6}$

At the 10th anniversary of hurricane Katrina, the city has changed. Only 40 of city's 72 neighborhoods have recovered at least $90 \%$ of their pre-storm population (Plyer and Mack, 2015). A quarter of the people who filed federal tax returns from New Orleans in 2005 were filing them from somewhere else in the country (Deryugina et al., 2014). This $25 \%$ will probably never return. ${ }^{7}$

Demographic structure and human capital and income distribution also changed. For instance, though both Black and White populations declined, the Black population fell by $44.5 \%$ between 2000 and 2013,

\footnotetext{
${ }^{2} 96 \%$ of Orleans Parish residents evacuated and $82 \%$ stayed away for more than 2 weeks (Geaghan, 2011). The U.S. Census Bureau (2008) estimated that $64 \%$ of the July 1, 2005 residents of Orleans Parish remained away on January 1 of 2006 , more than 4 months after the storm.

${ }^{3}$ Authors' calculation based on IPUMS data.

${ }^{4}$ Louisiana Department of Education, "Accountability Reports," http://www.doe.state.la.us/lde/pair/2069.asp and http://www.doe.state.la.us/lde/pair/2228.asp.

${ }^{5}$ http://www.sec.state.la.us/elections/MISC/091804-turnout.pdf. Ballot included elections for a majority of the local School Board seats. The turnout percentage is based on votes for Criminal Sheriff, the election with the largest number of votes cast. School Board votes were actually lower.

${ }^{6}$ The Boston Consulting Group, "The State of Public Education in New Orleans, June 2007," as reported in the publication "A Brief Overview of Public Education in New Orleans, 1995-2009" by the New Schools for New Orleans: http://newschoolsforneworleans.org/downloads/nsno_\%20EducFactSheet.7.09.pdf.

${ }^{7}$ Our calculations from IPUMS (2015) data show that Orleans Parish population was still more than $25 \%$ lower in 2013 than it had been in the year 2000: it declined from 481,142 in the year 2000 and still stood at only 352,097 in 2013. U.S. Census Bureau (2015) data shows the population of Orleans Parish declined from 484,674 in the year 2000 to 343,829 in 2010. Estimates for 2014 place it at 384,320, still $21 \%$ below where it stood nearly 15 years earlier.
} 
whereas the White population was only $9.8 \%$ lower. $^{8}$ The areas of lowest income in 2005 have the lowest return rates. Public housing communities were demolished. The 2015 residences receiving mail in the Desire, Florida, and Iberville public housing developments stands at $71 \%, 0.9 \%$, and $0.1 \%$ of their 2005 levels, respectively, and the Lower 9th Ward was at 36.7\% (The Data Center, 2015b, Table 1).

The average educational attainment of adults increased: the share with at least a high school degree rose from $75 \%$ in 2000 to to $85 \%$ in 2013 , close to the national average of $87 \%$. At the same time, the share with a college degree rose from $26 \%$ to $36 \%$, a full six points higher than the national average (The Data Center, 2015a). This obviously did not happen because the entire population became more educated. We believe many of the city's changes happened because of selective return. ${ }^{9}$

Deryugina et al. (2014) use synthetic control methods to analyze a 1999 to 2010 panel of individual IRS tax return data. They show that, after an initial dip, adjusted gross income of New Orleanians was significantly higher than it would have been without the storm. Wages followed a similar pattern, dipping $15 \%$ below the control group in 2006, equaling control wages in 2007 , and then rising to surpass them by 10\%. The unemployment rate jumped above control levels in 2005, and 2006, but dipped significantly below the control group in 2007 and after. ${ }^{10}$

The educational system was even more dramatically transformed. And, while the impacts on learning are still being evaluated, there is no doubt that an unprecedented amount of attention has been paid to improving New Orleans schools. The Cowen Institute Report (2005) wrote: "A hybrid model where charter schools outnumber district-operated schools two to one has resulted in a newfound emphasis on innovation and school autonomy. While significant challenges remain, the new model of delivering education to the city's youth has begun to yield results. Today, the once academically, morally and financially bankrupt system is nationally recognized as a potential model for urban school system reform." Jabbar (2015a) writes that: "The New Orleans school-choice market, consisting overwhelmingly of open-enrollment charter schools, is arguably the most competitive district ever created in the United States." Now, $84 \%$ of New Orleans students attend charter schools (Jabbar, 2015b). New Orleans has also become something of a world leader in other areas, including storm water innovation (GNO, 2013 and Shrinath and Plyer, 2015), health care delivery (Sebelius, 2015), and eco-friendly transportation (Huffington Post, 2015).

Such drastic change in only 10 years would have been unimaginable without the Katrina stimulus: wages and educational expenditures are higher, the population is smaller, but more skilled, average educational attainment is higher than it used to be, and public services have improved. The post-Katrina equilibrium

\footnotetext{
${ }^{8}$ See also Groen and Polivka (2010).

${ }^{9}$ McIntosh (2008) reports that New Orleans evacuees living in Houston up to August of 2006 were on average less educated than their hosts; $58 \%$ had at most a high school education, compared to $47 \%$ of non-evacuee Houston residents. Also, De Silva et al. (2010) find a persistent downward effects of New Orleans migrants on Houston's unskilled wage rate.

${ }^{10}$ Deryugina et al. (2014) also provides a review of the empirical literature regarding the effects of Katrina.
} 
of our model captures many of these effects.

\subsection{Key elements of the model}

There are three key elements in our model. The first is that some agents are born with a locational attachment to their city. This helps to capture the pre-K reality of New Orleans, ${ }^{11}$ where wages and the quality of public services were much worse than in other parts of the country and yet the population was stable, a fact otherwise inconsistent with full mobility of identical agents across jurisdictions. Thus, we consider two types of agents that differ in their endowments. Agents are born either with an endowment $e_{1}$ of good 1 or with a one unit endowment of good 2. Both are fully mobile across cities. For simplicity we call these goods "skilled" and "unskilled" labor. We assume that all unskilled agents are identical; however, skilled agents differ in their attachment to the city. We capture the attachment as a productivity enhancement to $e_{1}$ in New Orleans that is lost by moving. We measure the productivity enhancement with the function $a(\cdot) \geq 1$. Hence, skilled agent $j$ is endowed with an operational local "skill" level $e_{1}(j)=e_{1} \cdot a(j)$ when she lives in New Orleans, but her endowment reverts to $e_{1}(j)=e_{1}$ if she leaves. ${ }^{12}$

The second key element of our model is a fixed cost of moving for each type that captures all of the pecuniary and psychic costs associated with moving away from New Orleans. Information plays an important role here. It is reasonable to posit that, in normal circumstances, it is costly for people who live in one city to obtain precise information on the opportunities for work, schools, and general living conditions in another city. So, to the extent that people choose not to incur those costs, the benefits of moving remain uncertain, resulting in migrational equilibria that are consistent with non-negligible differences in quality of life across disparate local economies. However, a long evacuation after a major disaster forces these information costs on the evacuees, and they then learn about labor markets, schools, and quality of life in other places. This means that, when the disaster has passed, marginal agents return only if the quality of life in the city of origin is higher than it used to be. We model the effect of Hurricane Katrina as reducing the moving cost out of New Orleans or, equivalently for our purposes, as a perceived improvement in the utility of living outside New Orleans brought about by the reduction in uncertainty following the forced evacuation experience. ${ }^{13}$

The third and final key component of our model is a congestable public good (see Scotchmer, 2002),

\footnotetext{
${ }^{11}$ We adopt the new local vernacular and refer to "pre-K" and "post-K" equilibria.

${ }^{12}$ We can think of many examples. For instance a cab driver, a physician in private practice, a mobster or a lawyer can all carry their professions with them-driving, medical practice, extortion-but they will all be less productive in a new community. Surely, locational attachments are present in many communities. Nonetheless, New Orleanians are well-known to be exceptionally attached to their city. Groen and Polivka (2008) explore whether early labor market outcomes for evacuees differed depending on whether they returned to New Orleans or not. They find that individual characteristics including education and the extend of damage to their original neighborhoods mattered most. In our model the physical destruction of a neighborhood could be interpreted as a reduction in the attachment parameter, if it reduces market productivity.

${ }^{13} \mathrm{~A}$ different approach is to model the effect of disasters as a destruction in capital and current output, see, e.g., AlbalaBertrand (1993).
} 
"public education," which is publicly provided and affects the utility of returning to the city. The different responses of skilled and unskilled agents to Katrina determine the changes in the level of provision of public education. Therefore, our analysis of the effects of a disaster on public good provision complements that of Anbarci et al. (2005), who deal with the effects of a public good, "disaster mitigation," on the destructive potential of a disaster. ${ }^{14}$

\subsection{Our results}

We find that skills return in greater proportion than unskilled labor, thus lowering the returns to skill and increasing the wage for unskilled labor. The post-K New Orleans is smaller and more skill-intensive; moreover, among skilled agents, the larger the New Orleans specific productivity, the larger the likelihood of return. This three-fold effect on population makes predicting the evolution of income inequality a tricky exercise. In particular, if unskilled agents earn less than the poorest skilled agent - a realistic assumptionthen there arises the possibility of "middle class flight" from the city. We identify a sufficient condition on the function $e_{1}(\cdot)$ such that this is not the case and, in the post-K equilibrium, income distribution becomes more equal. Furthermore, we link this condition to the shape of the initial distribution of income. In particular, we show that commonly used statistical functions satisfy our condition, including the class of log-concave densities. Per-capita expenditure on public education increases, because skilled agents see this as a convenient way to induce more unskilled agents to return and mitigate the increase in their wage. In terms of utility, skilled labor is unambiguously worse off because the unskilled wage rate must rise. But even though their wages rise and the quality of public education goes up, unskilled workers end up being no more than exactly compensated for their cost of returning to the city. Therefore, the main technical contribution of our theoretical exercise is to show that a simple, standard framework accounts for the apparent stylized facts.

Overall, our main message is one of tempered optimism. Yes, there are improvements in terms of education and wages. However, the main reason for these improved outcomes is that, even interpreting Katrina as a classless shock, many among the unskilled do not return to the city. In our model this lack of incentive to return is structural and it has an indirect, positive equilibrium effect on education levels and unskilled wages. However, the non-return of many among the poor/unskilled to return is problematic from an ethical point of view.

The rest of the paper proceeds as follows. Section 2 describes the model and calculates equilibrium. Section 3 contains our results about the effects of Katrina on population, wages, income distribution, and level of public good provision. We perform this analysis both in the short-run, where the political process is

\footnotetext{
${ }^{14}$ Edwards (2015) reviews other papers on the political economy of disaster mitigation.
} 
not allowed to adjust so that the level of public good is constant, and in the long-run where it can adjust. Section 4 concludes. Technical proofs are in the Appendix.

\section{The Model}

\subsection{Description of the Economy}

We consider a two-good, exchange economy with a continuum of agents of two types, distinguished by the nature of their endowment. Type 1 agents, referred to as "skilled", are endowed with good 1, they are indexed by $j \in R^{+}$, and each has an "attachment premium" to the city, $a(j) \geq 1$. The function $a(\cdot)$ is continuous and, without loss of generality, strictly decreasing. Further, we assume $\left|a^{\prime}\right|<\infty$. If any skilled agent leaves the city, then the attachment premium is lost and the endowment becomes $e_{1}>0$, identical across skilled agents. In contrast, within the city of New Orleans the attachment premium applies, so that the endowment of skilled agent $j$ takes on the value $e_{1}(j)=e_{1} \cdot a(j)$. Type 2 agents, referred to as "unskilled", are all identical. They are endowed with one unit of good 2, no matter where they live.

The common utility function of all agents is

$$
u\left(c_{1}, c_{2}, g\right)=\log c_{1}+\log c_{2}+\log g
$$

where $c_{1}$ is the consumption of good $1, c_{2}$ is the consumption of good 2 , and $g$ is the consumption of education. Consumption of goods 1 and 2 is determined in a competitive equilibrium. Good 1 is the numeraire and the price of good 2 is $P$. Education is produced using good 1, with a one-to-one technology.

There are private and public school options available to all agents. ${ }^{15}$ Schooling can be acquired privately in any amount desired in exchange for good 1, or it can be obtained for free in a public school, at the pre-specified level $g_{m}$. For simplicity, we assume agents that take the public option cannot privately add to this level. ${ }^{16}$

This is a first approximation that captures the effects of many real-life factors, such as time constraints, that would add a level of complexity unnecessary for our analysis. Public education is financed by a budgetbalancing tax on the endowment of skilled agents. For simplicity, we consider a flat tax rate $t$. The choice of policy therefore reduces to the one-dimensional variable $g_{m} \cdot{ }^{17}$

\footnotetext{
${ }^{15}$ The choice between public and private education has been extensively modeled in the literature, see Gradstein and Justman (1996), for instance.

${ }^{16} \mathrm{~A}$ model that considers the implications of relaxing this constraint is Bearse et al. (2005).

${ }^{17}$ Our modeling choice for taxation is meant to capture institutional features such as the homestead exemption, which aim to make local taxation more progressive. Indeed, the largest source of financing for the City of New Orleans is the real estate tax, which is subject to a homestead exemption of $\$ 75,000$ of assessed value. In 2004 there were 149,745 property tax payers. Of these, 73,978 filed for a homestead exemption, of which $36,246(49 \%)$ were entirely covered by the homestead exemption
} 
Any agent can leave the city to earn a reservation utility by paying a one-time moving cost. We incorporate this cost in the reservation utilities, which we denote with $\log R_{s}$ for skilled agents and $\log R_{u}$ for unskilled agents. In our choice of monikers for agents and of taxation structure we have made the implicit assumption that skilled agents are "richer" than unskilled ones. This is formally accomplished in equilibrium, as the next Section shows, with the assumption that $R_{s}$ is larger than $R_{u}$.

\subsection{Equilibrium}

We define an equilibrium as a collection $C$ of:

- Consumption and education choice functions for each agent in the city

- Location decisions

- Tax rate $t$

- Policy variable $g_{m}$

- Price $P$

that jointly satisfy these conditions:

1. Each agent maximizes utility subject to her budget constraint, taking as given $t, g_{m}$, and $P$. The resulting optimal consumption and education choices are such that markets clear, given location decisions.

2. Each agent, fully anticipating the optimal decision in Condition 1, chooses the utility-maximizing location.

3. The tax rate $t$ balances the budget, given $g_{m}$, the education decisions in Condition 1 , and the location decisions in Condition 2.

4. The level $g_{m}$ is such that there exists no other collection that satisfies Conditions 1-3, with $\tilde{g}_{m} \neq g_{m}$, in which the utility of any agent that locates in the city (in the current collection $C$ ) is increased. In the determination of $g_{m}$ we assume that each agent fully anticipates all implications on prices, taxes, and city population. ${ }^{18}$

and so paid no real estate taxes. (Louisiana Tax Commission, 2003, 2005, 2007, 2008, 2014.)

${ }^{18}$ We can sidestep more complex descriptions of the political structure because, given the logarithmic utility in (1), all agents end up preferring the same level of $g_{m}$, as clarified in the discussion following Proposition 1, infra. A more general treatment can be found in Conley and Konishi (2002). 
We now characterize equilibrium and show its existence and uniqueness. For clarity, the characterization is broken up in a series of Lemma. We start with the analysis of individual consumption and schooling decisions.

Skilled agents that acquire education privately choose $c_{1}, c_{2}$, and $g$ to maximize the utility in (1) subject to the budget constraint

$$
c_{1}+P c_{2}+g \leq e_{1}(j)(1-t) .
$$

Any skilled agent that opts for public provision has the same utility function expressed in (1), but the budget constraint becomes

$$
c_{1}+P c_{2} \leq e_{1}(j)(1-t) .
$$

In addition, this agent faces the public provision constraint

$$
g=g_{m}
$$

Unskilled agents solve similar problems. The only change in their utility-maximization problem is the right-hand side of the budget constraint. Since unskilled agents are endowed with one unit of good 2 and do not pay taxes, their real income is simply $P$.

Lemma 1 (Education and consumption choices of skilled agents). The consumption and education decisions of skilled agent $j$ that acquires education privately are

$$
c_{1}=\frac{1}{3} e_{1}(j)(1-t), c_{2}=\frac{1}{3 P} e_{1}(j)(1-t), g=\frac{1}{3} e_{1}(j)(1-t)
$$

The consumption and education decisions of skilled agent $j$ that opts for public education are

$$
c_{1}=\frac{e_{1}(j)(1-t)}{2}, c_{2}=\frac{1}{P} \frac{e_{1}(j)(1-t)}{2}, g=g_{m}
$$

The indirect utility of skilled agent $j$ who acquires education privately is

$$
\log \frac{1}{P}\left(\frac{e_{1}(j)(1-t)}{3}\right)^{3}
$$

while if she opts for public provision her utility is

$$
\log \frac{1}{P}\left(\frac{e_{1}(j)(1-t)}{2}\right)^{2} g_{m}
$$


Therefore, a skilled agent $j$ opts for the public system if and only if $e_{1}(j)<e_{1}^{*}$, where

$$
e_{1}^{*} \cdot(1-t)=\frac{27}{4} g_{m}
$$

Beyond characterizing the optimal consumption and education decisions, Lemma 1, with proof in the Appendix, shows that only relatively rich agents attend private school. The intuitive explanation of this result exploits the trade-off between having flexibility in choosing the level of education vs. bearing the full cost of education. The richer an agent, the more important flexibility becomes relative to bearing the cost of education. Therefore, private education becomes more attractive with income.

Thus, another interesting remark follows from Lemma 1: the per-capita amount of education acquired privately is strictly larger than the per-capita public expenditure $g_{m}$. Moreover, a discrete gap exists between the two. Indeed, using $(3),(4)$, and $e_{1}^{*}$, one can verify that the smallest amount of private education acquired by any skilled agent is more than double the amount provided by public schools. Intuitively, no private choice of education "close" to $g_{m}$ can be optimal. This happens because the benefits of education increase continuously, while the cost of self-financing has a discrete jump, of size not smaller than $g_{m}$, at the switch from public school to private. In other words, the distribution of school quality is discontinuous at $g_{m}$ because it makes no sense to bear the full cost of schooling to ensure only a marginally superior education. Note that our model is successful in replicating stylized facts about education in New Orleans, albeit crudely. If we equate resources spent with education quality, the quality of private education is markedly superior to the quality of public education.

Unskilled agents are simpler to analyze, because they all make the same choice, which we describe in the following Lemma. (The proof is similar to that of Lemma 1 and therefore omitted.)

Lemma 2 (Education and consumption choices of unskilled agents). The education and consumption choices of an unskilled agent that opts for public provision are

$$
c_{1}=\frac{P}{2}, c_{2}=\frac{1}{2}, g=g_{m}
$$

resulting in indirect utility equal to

$$
\log \frac{1}{4} P g_{m}
$$

The education and consumption choices of an unskilled agent that acquires education privately are

$$
c_{1}=\frac{1}{3} P, c_{2}=\frac{1}{3}, g=\frac{1}{3} P
$$


resulting in indirect utility equal to

$$
\log \frac{P^{2}}{27}
$$

Therefore, all unskilled agents opt for public provision if and only if

$$
g_{m}>\frac{4}{27} P
$$

Having established the individual-level choices, we now turn to the determination of the economy-wide variables for prices, tax rates, and population, given a level of public expenditure on schooling $g_{m}$. The equilibrium price and tax rate are determined by the requirements of market clearing and a balanced government budget. These requirements depend on three conditions about population size and composition, endowments, and the consumption of education. First, we need the endogenous measures of skilled and unskilled agents in the city, denoted by $N_{s}$ and $N_{u}$ respectively. These measures come from the constraint that all $N_{u}$ unskilled agents and the marginal skilled agent $j=N_{s}$ must be indifferent between living in the city, or receiving their reservation utilities elsewhere. Second, city population and composition determine total endowments, which determine prices in equilibrium. The total endowment of good 1 in the economy is $E_{1}$, defined as

$$
E_{1}=\int_{0}^{N_{s}} e(j) d j
$$

The total endowment of good 2 in the city, $E_{2}$, is equal to $N_{u}$, since every unskilled agent brings one unit to the city. In the third and final condition, we account for the choice of schooling, because it determines demand and therefore equilibrium prices and tax rates.

To complete the characterization of equilibrium, the level of public expenditure $g_{m}$ is chosen to satisfy Condition 4 in the definition of equilibrium. Proposition 1 below shows a condition that guarantees existence and uniqueness of an equilibrium in which all skilled agents opt for private provision and all unskilled agents attend public school. Intuitively, this happens when the reservation utility for skilled agents is sufficiently large relative to that of unskilled agents, so that only relatively rich skilled agents live in the city. This implies a very unequal income distribution, matching another fact about the New Orleans economy. Proposition 1 furthermore derives the equilibrium level of public school education $g_{m}$.

Proposition 1 (Existence and uniqueness of equilibrium). A unique equilibrium exists if

$$
\frac{R_{s}}{R_{u}} \geq\left(\frac{3^{4}}{40}\right)^{2} \approx 4.1
$$


In such an equilibrium, the measure of skilled agents $N_{s}^{E Q}$ is the unique value of $N_{s}^{E Q}$ which solves

$$
e_{1}\left(N_{s}^{E Q}\right)=\frac{6 R_{u}+g_{m}^{2}}{R_{u}} \sqrt[3]{\frac{R_{s}}{g_{m}} \cdot \frac{R_{u}}{2}}
$$

The equilibrium measure of unskilled agents is

$$
N_{u}^{E Q}=\frac{g_{m}}{6 R_{u}+g_{m}^{2}} E_{1}=\frac{g_{m}}{6 R_{u}+g_{m}^{2}} \int_{0}^{N_{s}^{E Q}} e(j) d j,
$$

the equilibrium price is

$$
P^{E Q}=4 \frac{R_{u}}{g_{m}}
$$

the equilibrium tax

$$
t^{E Q}=\frac{g_{m}^{2}}{6 R_{u}+g_{m}^{2}},
$$

and the level of public good provided solves

$$
g_{m}^{2}=\frac{6}{5} R_{u}
$$

Proof. We proceed by construction. For the moment, fix the level of public provision $g_{m}$ and assume that all skilled agents acquire education privately and that all unskilled agents opt for public provision. At the end of the proof, $g_{m}$ will be endogenously determined and the assumptions will be verified. We begin with the determination of prices and tax rates. Using the expression for skilled and unskilled demands, that is, conditions (3) and (8), the market clearing condition is

$$
\frac{2 \cdot E_{1} \cdot(1-t)}{3}+P \cdot \frac{N_{u}}{2}=E_{1}(1-t)
$$

for any given population size and composition. Taxes are determined by the budget balance constraint:

$$
t=\frac{N_{u} g_{m}}{E_{1}}
$$

Together, the two previously displayed equations yield $P$, the price at which good 2 is trading for good 1 :

$$
P=\frac{2}{3} \frac{E_{1}-N_{u} g_{m}}{E_{2}}
$$

As expected, equation (19) shows that $P$ is increasing in $E_{1}$ and decreasing in $E_{2}$. Note as well that the burden of providing education falls partly on unskilled agents, through its effect on $P$.

Now, we turn to population. Using the reservation utilities in Lemma 1 and 2, the conditions that 
determine $N_{s}$ and $N_{u}$ are

$$
\frac{1}{4} P g_{m}=R_{u}
$$

for the unskilled agents, and

$$
\frac{1}{P}\left(\frac{e_{1}\left(N_{s}\right)(1-t)}{3}\right)^{3}=R_{s}
$$

for the marginal skilled agents. Conditions (20) and (21) ensure all unskilled agents and the marginal skilled are indifferent between living in the city and receiving their reservation utility elsewhere. Therefore, using (19), (20), and noting that $E_{2}=N_{u}$, the equilibrium measure of unskilled agents is

$$
N_{u}^{E Q}=\frac{g_{m}}{6 R_{u}+g_{m}^{2}} E_{1}
$$

which verifies (15), with associated equilibrium price

$$
P^{E Q}=4 \frac{R_{u}}{g_{m}}
$$

which verifies (16), and equilibrium tax

$$
t^{E Q}=\frac{g_{m}^{2}}{6 R_{u}+g_{m}^{2}}
$$

which verifies (17). From (15), $N_{u}^{E Q}$ is a one-to-one (linear) function of $E_{1}$, which in turn is a one-toone (strictly increasing) function of $N_{s}$. Therefore, if the equilibrium population of skilled agents, $N_{s}^{E Q}$, is uniquely determined, only one candidate equilibrium corresponds to each $g_{m}$. Using (15), (16), and (21) we obtain the following relation:

$$
\left(e_{1}\left(N_{s}\right)\left(1-t^{E Q}\right)\right)^{3}=27 \cdot 4 \cdot \frac{R_{s} \cdot R_{u}}{g_{m}}
$$

Substituting (17) into (22) and recalling that $e(\cdot)$ is monotone, the equation that uniquely determines $N_{s}^{E Q}$ is:

$$
e_{1}\left(N_{s}^{E Q}\right)=\frac{6 R_{u}+g_{m}^{2}}{R_{u}} \sqrt[3]{\frac{R_{s}}{g_{m}} \cdot \frac{R_{u}}{2}},
$$

which verifies (14). Therefore, as long as the level of $g_{m}$ is such that skilled agents acquire education privately and unskilled agents opt for public provision, all equilibrium variables beyond $g_{m}$ are uniquely determined by Conditions 1-3 in the equilibrium definition.

We now turn to the endogenous determination of $g_{m}$. The critical requirement in Condition 4 of the equilibrium definition is that agents fully anticipate the effects of different levels of $g_{m}$ on the economy. This implies that utility for unskilled agents is the same for all levels of $g_{m}$, because when $g_{m}$ rises $P$ falls: immigration or emigration will force any unskilled agent's utility to be exactly the outside reservation 
utility. Therefore, we focus on the preferences of skilled types over $g_{m}$. A skilled type's utility is given in (5). Substituting equilibrium values in (16) and (17), we obtain that the derivative of the indirect utility in (5) with respect to $g_{m}$ is

$$
\frac{6 R_{u}-5 g_{m}^{2}}{g_{m}\left(6 R_{u}+g_{m}^{2}\right)}
$$

therefore, by strict quasi-concavity, $g_{m}^{2}=6 R_{u} / 5$ is the unique maximizer of (5). Thus, $g_{m}=\sqrt{6 R_{u} / 5}$ is the public school quality level that the skilled population provides for their unskilled fellow citizens. Note that public school quality depends directly on $R_{u}$, the opportunities of unskilled labor outside New Orleans net of moving costs.

To complete the proof, we now verify consistency of school choices. For unskilled agents to opt for public provision, using (12) we need

$$
g_{m}^{2} \geq \frac{16}{27} R_{u}
$$

which is satisfied by (18). So that all skilled agents choose private provision, we need $e_{1}\left(N_{s}^{E Q}\right)>e_{1}^{*}$, or, using (7) and (22),

$$
27 \cdot 4 \cdot \frac{R_{s} \cdot R_{u}}{g_{m}} \geq\left(\frac{27}{4} g_{m}\right)^{3}
$$

By (18), this last inequality reduces to condition (13) in the statement of Proposition 1.

Several interesting remarks follow from Proposition 1. First, as the proof of Proposition 1 makes clear, the assumption of a logarithimic utility function considerably simplifies the description of the economy because skilled agents unanimously prefer the same level of public schooling to be provided to the unskilled. With a more general utility function, an adjustment to Condition 4 in the definition of equilibrium would be necessary, for example specifying more in detail the characteristics of the political and voting processes. One important fact would be unchanged though: unskilled agents' utility would be the same for any value of $g_{m}$. This is a consequence of mobility and homogeneity of unskilled agents: immigration or emigration will force their utility to be exactly their outside reservation utility net of moving costs. ${ }^{19}$ Thus, even in more realistic models, as long as voting is costly and at least partially motivated by economic interest, we can expect skilled agents to have a larger incentive to vote than unskilled agents.

Second, note that, through the determination of $g_{m}$, skilled agents selfishly affect the total pool of unskilled labor by trading off the cost of financing public schools against lower prices that result from having a larger pool of unskilled workers in the city. ${ }^{20}$ In other words, increasing public school quality is a way of decreasing the price of the good that unskilled agents supply. This grim interpretation is made worse by an

\footnotetext{
${ }^{19}$ Berliant and Edwards (2004) show that reaching equilibrium in this way is unlikely to be efficient.

${ }^{20}$ This tradeoff is described in equations (16) and (17).
} 
additional fact: given the equilibrium price in (16), unskilled agents would choose a level of education higher than the equilibrium $g_{m}$ if there were no public schools. ${ }^{21}$ This implies that unskilled agents suffer from a reduction in flexibility. Moreover, note that the equilibrium level of public provision in (18) is increasing in the reservation utility $R_{u}$. Indeed, as (16) shows, an increase in $R_{u}$ translates into an increase in the price of the unskilled good $P$, and therefore it raises the unskilled agents' income and demands. ${ }^{22}$

Third, note that at the equilibrium level of public education provision, that is, when $g_{m}^{2}=6 R_{u} / 5$, the population of skilled agents is maximized, but overall city size is not. This can be seen by differentiating for $g_{m}$ the condition that determines the population of skilled agents in equilibrium. Using (14) we obtain that

$$
\operatorname{sign}\left(\frac{d e_{1}\left(N_{s}^{E Q}\right)}{d g_{m}}\right)=\operatorname{sign}\left(g_{m}^{2}-\frac{6}{5} R_{u}\right) .
$$

Since $e_{1}(\cdot)$ is decreasing, the smaller is $e_{1}\left(N_{s}^{E Q}\right)$, the larger $N_{s}^{E Q}$ becomes. Therefore, since at $g_{m}^{2}=6 R_{u} / 5$ the function $e_{1}(\cdot)$ attains a global minimum, $g_{m}^{2}=6 R_{u} / 5$ also maximizes $N_{s}^{E Q}$. But for total population, we have

$$
\left.\frac{d\left(N_{s}^{E Q}+N_{u}^{E Q}\right)}{d g_{m}}\right|_{g_{m}^{2}=\frac{6}{5} R_{u}}=\frac{6 R_{u}-2 g_{m}^{2}}{\left(6 R_{u}+g_{m}^{2}\right)^{2}} E_{1}=\frac{E_{1}}{12}>0
$$

using (15). Therefore, a higher $g_{m}$ would increase city size.

Finally, the equilibrium displays a marked income inequality, much as described in the motivating observations in the introduction. Simple algebra, along with (13), shows that $P^{E Q}<e_{1}\left(N_{s}^{E Q}\right)$. In other words, the value of the endowment of any unskilled agents is smaller than the value of the poorest skilled agent's endowment.

We conclude this section with the calculation of the Lorenz curve $l(x)$ in equilibrium. Since $P<e\left(N_{s}\right)$, the first agents to be added in order of increasing income are the unskilled, who are all identical. Therefore, for $x \in\left[0, \frac{N_{u}^{E Q}}{N_{u}^{E Q}+N_{s}^{E Q}}\right], l(x)$ is a straight line with $l(0)=0$ and $l\left(\frac{N_{u}^{E Q}}{N_{u}^{E Q}+N_{s}^{E Q}}\right)=\frac{P E_{2}}{P E_{2}+E_{1}}$. For $x \in$ $\left(\frac{N_{u}^{E Q}}{N_{u}^{E Q}+N_{s}^{E Q}}, 1\right]$, the expression for the Lorenz curve of market income is

$$
l(x)=\frac{P E_{2}}{P E_{2}+E_{1}}\left(1+\int_{\left(N_{s}^{E Q}+N_{u}^{E Q}\right)(1-x)}^{N_{s}^{E Q}} \frac{E_{1}}{P E_{2}} \frac{e(j)}{E_{1}} d j\right) .
$$

\footnotetext{
${ }^{21}$ This fact follows from the comparison of (10) and (18).

${ }^{22}$ Foreshadowing our results in the next Section, this discussion helps in explaining why, in response to increases in $R_{u}$, improving public schools' quality is a very effective way of inducing more unskilled agents to live in the city. Indeed, along with a direct increase in consumption of education, the utility cost of the reduction in flexibility in education choice is lessened, because $g_{m}$ becomes closer to the optimal, unconstrained level unskilled agents would choose for themselves, if they had to pay for it. Note that if public education provides externalities by teaching citizenship, respect for property and hygiene, then the motivation for preferring it to a higher wage for unskilled labor is strengthened.
} 


\section{After Katrina}

The hurricane has brought many changes: the housing stock has been depleted, the infrastructure of the city has been severely damaged, the spirit of citizens itself has been tested. All these circumstances, along with others, have an effect on the city's economy. We focus on a non-controversial aspect: all citizens have been displaced. In our model, this results in larger $R_{s}$ and $R_{u}$. Indeed, for a citizen of New Orleans that was considering moving out of the city before the hurricane, the relevant comparison involved the outside standard of living minus the moving cost. After the hurricane, the moving cost has already been incurred, albeit involuntarely. The decision to return to the city now involves a moving cost. A similar increase in reservation utilities may derive from other considerations, such as more familiarity with job markets, school systems, and support networks of cities other than New Orleans. Moreover, an identical mathematical effect obtains from considerations that reduce the utility of living in the city such as the cost of housing repairs or higher flood- and wind-damage insurance rates. For the rest of the analysis, we assume that the new reservation utilities satisfy (13), so that the characterization and uniqueness results of Proposition 1 remain valid.

Our results in this section follow from the comparative statics properties of equilibrium, which we summarize in Proposition 2.

Proposition 2 (Comparative statics). Changes to equilibrium are characterized by the following perturbation equations

$$
\begin{gathered}
\frac{\Delta N_{u}^{E Q}}{N_{u}^{E Q}}-\frac{e_{1}\left(N_{s}^{E Q}\right) N_{s}^{E Q}}{E_{1}} \cdot \frac{\Delta N_{s}^{E Q}}{N_{s}^{E Q}}+\frac{5}{6} \cdot \frac{\Delta R_{u}}{R_{u}}-\frac{2}{3} \cdot \frac{\Delta g_{m}}{g_{m}}=0, \\
\frac{e_{1}^{\prime}\left(N_{s}^{E Q}\right) \cdot N_{s}^{E Q}}{e_{1}\left(N_{s}^{E Q}\right)} \cdot \frac{\Delta N_{s}^{E Q}}{N_{s}^{E Q}}-\frac{1}{6} \cdot \frac{\Delta R_{u}}{R_{u}}-\frac{1}{3} \cdot \frac{\Delta R_{s}}{R_{s}}=0,
\end{gathered}
$$

and

$$
\Delta g_{m}=\frac{3}{5 g_{m}} \Delta R_{u}
$$

Proof. Follows by applying the implicit function theorem to the equilibrium equations in Proposition 1. For example, (24) obtains by first log-linearizing (15) into

$$
\log N_{u}^{E Q}=\log \frac{g_{m}}{6 R_{u}+g_{m}^{2}}+\log E_{1},
$$

then totally differentiating to derive

$$
\frac{\Delta N_{u}^{E Q}}{N_{u}^{E Q}}-\frac{e_{1}\left(N_{s}^{E Q}\right) N_{s}^{E Q}}{E_{1}\left(N_{s}^{E Q}\right)} \frac{\Delta N_{s}^{E Q}}{N_{s}^{E Q}}=-\frac{6}{\left(6 R_{u}+g_{m}^{2}\right)} \Delta R_{u}+\frac{g_{m}^{2}-6 R_{u}}{\left(6 R_{u}+g_{m}^{2}\right)} \frac{\Delta g_{m}}{g_{m}}
$$


and finally substituting $g_{m}^{2}=6 R_{u} / 5$ from (18). Condition (25) is similarly obtained, and (26) follows from (18).

In Proposition 2, we express (24) as a function of $\Delta g_{m}$ in order to analyze the short-term transition period where the level of public schooling may not yet have adjusted. With a longer time horizon, $\Delta g_{m}$ is given in (26), and can be substituted into (24). Two corollaries follow immediately, and appropriately match evident empirical facts about the "new" New Orleans.

Corollary 1 (Population). The after-Katrina population of both kinds of agents is smaller.

Corollary 2 (Prices). The after-Katrina price of good 2 is higher.

Proof. The proof of both corollaries follows immediately from (16), (24), and (25). Indeed, since $\frac{1}{6} \frac{\Delta R_{u}}{R_{u}}+$ $\frac{1}{3} \frac{\Delta R_{s}}{R_{s}}>0$ and $e_{1}^{\prime}<0$, then $\frac{\Delta N_{s}^{E Q}}{N_{s}}<0$ from (25). In the short-term, $\frac{\Delta g_{m}}{g_{m}}=0$, which then implies $\frac{\Delta N_{u}^{E Q}}{N_{u}^{E Q}}<0$ from the first equation. In the long-term, $g_{m}$ changes according to $g_{m}^{2}=\frac{6}{5} R_{u}$, so we have $\frac{2}{3} \frac{\Delta g_{m}}{g_{m}}=\frac{1}{3} \frac{\Delta R_{u}}{R_{u}}$, which substituted into (24) reduces the absolute value of $\frac{\Delta N_{u}^{E Q}}{N_{u}^{E Q}}$, but it is insufficient to change its sign. In the short-run, since $P^{E Q}=4 R_{u} / g_{m}$, then $P^{E Q}$ clearly increases. In the long-run, substituting $g_{m}=\sqrt{\frac{6}{5} R_{u}}$ into the value for $P^{E Q}=4 R_{u} / g_{m}$ and then differentiating for $R_{u}$, we still obtain that $P^{E Q}$ increases.

It is worth noting that while population falls and price rises both in the short and in the long-term, the magnitude of changes is smaller if $g_{m}$ is allowed to adjust. Moreover, while the algebra involved is simple, the change in the terms of trade in Corollary 2 just described plays an important role in the welfare comparison of agents that live in the city before and after the hurricane. One may think that, since outside opportunities are better, agents that optimally decide to return must be better-off than before the storm, excluding the one-shot costs associated with the hurricane. This natural intuition is true, but only for marginal agents. In other words, the price of the good supplied by unskilled agents must increase, to induce at least some of them to return. This is not the case for skilled agents, because they are heterogeneous. Richer agents absorb the negative (for them) consequence of Katrina, i.e., the larger $P$ demonstrated in Corollary 2. Returning richer agents' utility is lower than it was before the storm, but still higher than $\log R_{s}$. This is because they strictly prefer living in New Orleans, but for the lone marginal agent. In analytical terms, (21) is binding only for the marginal skilled agent, but is slack for $j<N_{s}^{E Q}$. Proposition 3 summarizes the welfare effects on different types of agents.

Proposition 3. Any returning unskilled agent is exactly compensated for the increase in reservation utility due to the hurricane. On the contrary, all returning skilled agents are made worse-off. 
Proof. From (20), unksilled agents are exactly compensated. As for skilled agent $j$, her utility is given in (5). Substituting the equilibrium values in (16) and (17), simple algebra shows that $j^{\prime} s$ utility is decreasing in $R_{u}$. The result for skilled agents and the one for unskilled ones are true for $g_{m}$ fixed and for $g_{m}$ variable.

We now explore after-Katrina income inequality. A first step is to determine changes in the equilibrium population ratio of skilled to unskilled agents. Naturally, the larger the percentage change in the reservation utility of one type of agent, the larger the the percentage change in the population of that type of agent. For the rest of our analysis, to avoid favoring a particular direction of the changes, we maintain the assumption that reservation utilities for living outside the city change by the same percentage for skilled and unskilled agents. However, Corollary 2 shows that, even with identical percentage changes in reservation utilities, the terms of trade must change in favor of unskilled agents. Therefore, one may think that unskilled agents must have become relatively scarcer. This natural intuition must be amended because skilled agents are heterogeneous: an increase in $P$ implies that $E_{1}$ must rise with respect to $E_{2}$, not necessarily that the number of agents moves in favor of the skilled. If all skilled agents had the same endowment, the change in $E_{1}$ would result in a larger proportional change in type-1 agents. Inequality among skilled agents, however, implies that the poorer skilled agents are the ones that leave the city. An especially marked inequality among skilled agents might then require a very large change in skilled population to obtain the required percentage change in $E_{1}$. This reasoning shows that, while our results establish that there is "middle class flight" from New Orleans, it can become so substantial that it more than offsets the equalizing effect of higher wages for unskilled workers.

It turns out that the relation between average and marginal endowment of skilled agents plays a crucial role in determining the proportion of agent types in the after-Katrina city. Define the average endowment of good 1 from $j=0$ to $j=N$ as

$$
e_{1 a v g}\left(N_{s}\right) \equiv \frac{\int_{0}^{N_{s}} e_{1}(j) d j}{N_{s}}
$$

and define the ratio of average and marginal endowment as

$$
S\left(N_{s}\right) \equiv \frac{e_{1 a v g}\left(N_{s}\right)}{e_{1}\left(N_{s}\right)}
$$

As the upcoming Propositions 5 and 6 demonstrate, the condition ' $S\left(N_{s}\right)$ increasing' is of great importance for our results. Therefore, it is interesting to explore its relation with more standard ways of modeling income distributions. Denote with $h$ the hazard rate of the income distribution for skilled agents:

$$
h(y) \equiv \frac{f(y)}{1-F(y)},
$$


where $F(y)$ is the cdf of the income distribution of skilled agents and $f(y)$ is the respective density. Our next result shows that $S\left(N_{s}\right)$ is increasing if $h$ is increasing. A sufficient condition is that $f$ is log-concave.

Proposition 4 (Log-concavity). If the density of skilled agents' income is log-concave, then $h$ is increasing (Bagnoli and Bergstrom, 2005). If $h$ is increasing, then $S\left(N_{s}\right)$ is increasing.

The following proposition establishes a sufficient condition for unskilled agents to become relatively more scarce in the after-Katrina city. The proofs of this and following results are technical, and they can be found in the Appendix.

Proposition 5 (Relative composition of population). If $\frac{\Delta R_{u}}{R_{u}}=\frac{\Delta R_{s}}{R_{s}}>0$ and $S\left(N_{s}\right)$ is increasing, then

$$
\left|\frac{\Delta N_{s}^{E Q}}{N_{s}^{E Q}}\right|<\left|\frac{\Delta N_{u}^{E Q}}{N_{u}^{E Q}}\right|
$$

It turns out that the same sufficient condition in Proposition 5 causes inequality to be reduced after Katrina. (The comparison of Lorenz curves is illustrated in Figure 1.)

Proposition 6 (Inequality is reduced). If $\frac{\Delta R_{u}}{R_{u}}=\frac{\Delta R_{s}}{R_{s}}>0$ and $S\left(N_{s}\right)$ is increasing, then

$$
l_{A K}(x)>l_{B K}(x), \forall x \in(0,1),
$$

where we denote the Lorenz curve before Katrina as $l_{B K}$ and the one after the storm as $l_{A K}$.

$\%$ of income

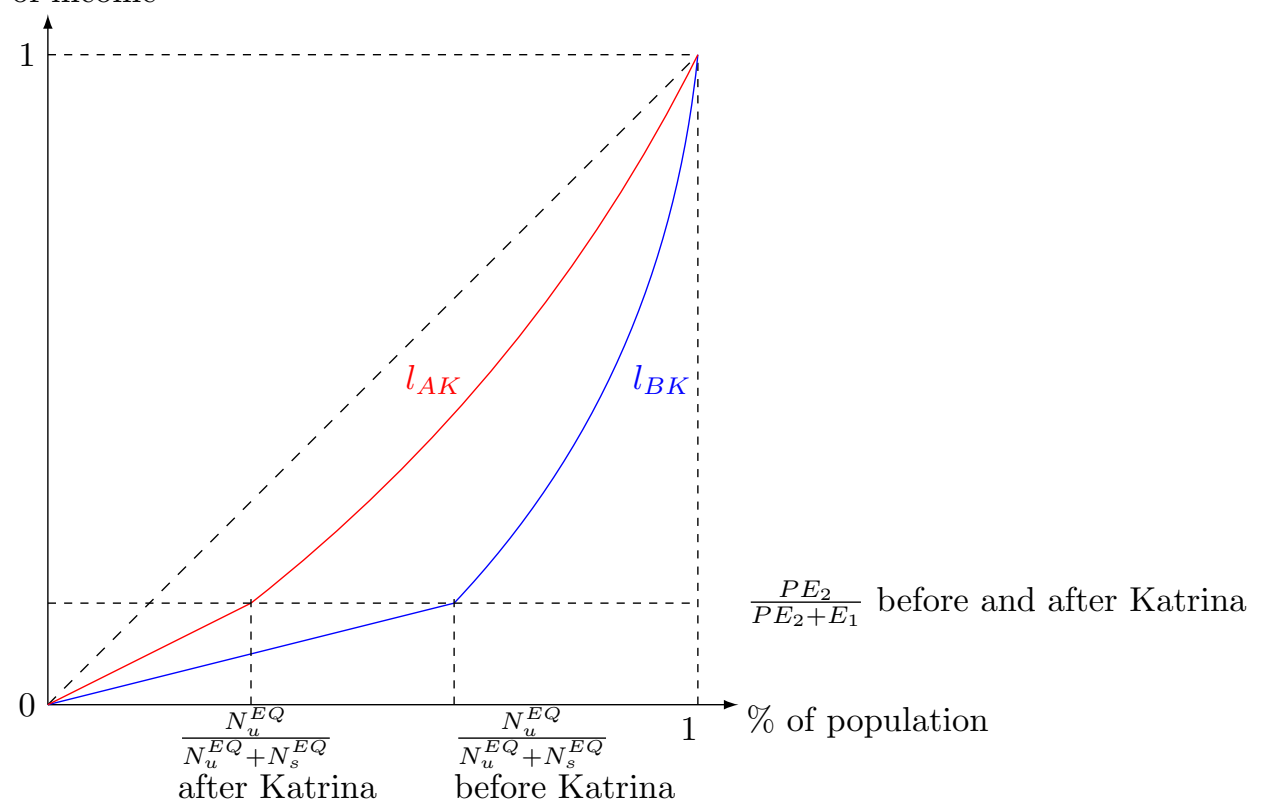

Figure 1: Lorenz curves before and after Katrina. 
Finally, we explicitly consider the effects of Katrina on the levels of schooling, both publicly provided and privately chosen, and taxes. Proposition 7 summarizes our results.

Proposition 7 (Education and taxes). Comparing the after Katrina levels with the situation before the storm

1. Per-pupil public school education level is higher.

2. Per-pupil private school education is higher.

3. Tax rates are unchanged

Proof. Part 1 follows immediately from (26) in Proposition 3. The intuition for the result that the per-pupil public school education level is higher is the following. Unskilled agents are all marginal; therefore, in order for them to be willing to incur the cost of returning to New Orleans, at least one of two things must happen: they must receive a higher compensation for their endowment, i.e., $P$ must rise, or they must receive better public services, i.e., $g_{m}$ must rise. Actually, both happen in equilibrium. Corollary 2 shows that unskilled agents' income and demands increase as $P$ rises. Thus, the gap between the desired level of education and the one actually provided becomes larger, implying that the utility cost of the reduction in flexibility incurred by attending public school increases. Therefore, from the point of view of skilled agents, increasing $g_{m}$ is an especially effective way of inducing more unskilled agents to live in the city and moderate the increase in $P$ : along with a direct increase in consumption of education, an increase in $g_{m}$ lessens the utility cost of the reduction in flexibility. The result in Part 2 that per-pupil private school education is higher depends on the fact that only relatively rich skilled agents return to the city and that the level of education chosen by skilled agent $j$ is unaffected by Katrina. In turn, this depends on the result in Part 3 that tax rates are unchanged by Katrina. To see these last two facts note that, using (3), the optimal choice of the privately acquired $g$ depends only on the equilibrium tax rate $t$, determined in (17). Since $g_{m}$ has adjusted after Katrina so that $g_{m}^{2}=6 R_{u} / 5, t$ turns out to be constant in equilibrium, so $g$ is unchanged as well. Therefore, because poorer skilled agents do not return, the average level of spending on private education increases. Clearly, the implication in Part 3 that $t$ is constant and therefore that the education level chosen by agent $j$ is unchanged are dependent of the specific modeling assumption. However, the result that average private education spending increases is much more robust. Indeed, any individual-level effect on private education is likely to be swamped by the population-composition effect: skilled agents in New Orleans after Katrina have higher average income because poorer agents do not return. 


\section{Conclusion}

We construct a formal, theoretical model of the decision to return to New Orleans in the aftermath of Hurricane Katrina. In particular, we examine the post-Katrina population composition of the city, the evolution of its income distribution and of the welfare of its citizens, and the changes in the level of education privately and publicly provided. The key component of our model is a locational attachment to the city, operationalized as a productivity enhancement to skilled workers that is lost by moving away.

Our overall results are positive for the new New Orleans. While smaller, the new New Orleans is more skill-intensive and education levels improve. Moreover, we provide a sufficient condition on the distribution of skills such that inequality is reduced. Finally, we show that our sufficient condition is closely related to standard representations of distributions, such as those with log-concave densities.

We view the contribution of our paper as two-fold. We interpret and explain some changes that are apparent in New Orleans post-Katrina. In this dimension, we regard the simplicity of our model as an asset, identifying some of the key elements common to disaster impact and the resilience of the recovery. Further, we provide a baseline framework for structuring and interpreting empirical research. We view our model as a starting point for further investigations. In particular, as far as the evaluation of empirical research, any findings that contradict our theoretical results deserve great attention, because such findings would require a careful - and interesting - rethinking of the simple forms of interactions we have chosen for our model. For instance, while the evidence on improvements in education is uncontroversial, there is less consensus about the evolution of income inequality. Shaughnessy et al. (2010) document a decrease in inequality right after the storm and up to 2007 that is consistent with our theoretical findings as depicted in Figure 1. However, these findings are not causal. More recent empirical evidence suggests that inequality has risen. ${ }^{23}$ Our model can provide guidance here. It points to a number of possible causes. First, it may be that there was middle class flight. This could result from unequal changes in reservation utilities. ${ }^{24}$ Second, new population groups (e.g., Hispanic workers and young volunteers) have been attracted to the city after the storm and we do not account for them in our model. Third, the income distribution of skilled agents may have been strongly bimodal, or may have otherwise violated the log-concavity condition in Proposition 4.

Moreover, our research can be of help in informing and guiding policy. Skilled agents in our model are perfectly selfish. Nonetheless, they find that it is in their best interest to improve the quality of public education after a Katrina-like disaster, even if they do not consume public education directly. This is a very

\footnotetext{
${ }^{23}$ Bloomberg (2015) reports that, of the 50 American cities ranked by Gini coefficient, New Orleans ranks second highest with a Gini coefficient value of 0.57 . This was up $5.4 \%$ since 2008 . See also Geagham (2011).

${ }^{24}$ Fussel et al. (2010), documents that African-Americans "suffered more severe housing damage which, in turn, led to their delayed return to the city." This is consistent with middle-class flight if African-Americans comprise a large proportion of the lower end of the skill distribution.
} 
stark example showing that the interactions within the whole community result in more than a zero-sum game. Some policy changes, such as improving public education, end up benefiting all agents. It goes without saying that a number of analogues to the improved public education of our framework can be expected in a richer model.

We conclude by sounding a note of caution. The driving force behind the statistical "improvements" in New Orleans is the selective return of evacuees, not a magical resilience that brings things back better. Our model predicts that New Orleans data should look "better" partly because the poorest and least educated population stay away in larger numbers, and partly because the wealthier returnees improve public services as a way of attracting more of the poor back. Also, our inability to theoretically rule out that disasters may cause an increase in inequality is interesting, if somewhat troubling. This suggests that special attention should be devoted to the topic of "middle-class flight." It is not difficult to imagine social situations in which members of the middle class function as glue between the lower and upper echelons of society, interacting with either at different times and different places. During periods of recovery, when resilience depends on the unity of an entire community, the potential loss of the middle class is cause of concern.

\section{$5 \quad$ Appendix}

Proof of Lemma 1. By concavity, the first order conditions are necessary and sufficient. They yield conditions (3) and (4). Substitution of these optimal choices into the utility function in (1) results in the indirect utility levels (5) and (6). The cutoff level $e_{1}^{*}$ equates (5) and (6). The difference between the indirect utility levels obtained through private schooling in (5) and public schooling in (6) is

$$
\log \frac{1}{P}\left(\frac{e_{1}(j)(1-t)}{3}\right)^{3}-\log \frac{1}{P}\left(\frac{e_{1}(j)(1-t)}{2}\right)^{2} g_{m}=\log e_{1}(j)(1-t) \frac{4}{27 g_{m}}
$$

Since the above is an increasing function of $e_{1}(j)$, public school is preferred by any agent $j$ such that $e_{1}(j)<e_{1}^{*}$. Similarly, if $e_{1}(j)>e_{1}^{*}$, then private school is preferred.

Proof of Proposition 4. The first implication follows immediately from Corollary 2 in Bagnoli and Bergstrom (2005): $\log$-concavity of the density $f$ implies $h$ increasing. Next, we establish the result that $h$ increasing implies $S\left(N_{s}\right)$ increasing with two Lemma.

Lemma 3. $S\left(N_{s}\right)$ is increasing if the following condition holds:

$$
e^{\prime}\left(N_{s}\right)+N_{s} e^{\prime \prime}\left(N_{s}\right)<0
$$


Proof of Lemma 3. In a right neighborhood of $N_{s}=0, S\left(N_{s}\right)$ is increasing, because

$$
\lim _{N_{s} \rightarrow 0} S\left(N_{s}\right)=1
$$

and

$$
\forall N_{s}>0, S\left(N_{s}\right)>1
$$

since $\frac{E\left(N_{s}\right)}{N_{s}}$ is decreasing by $e\left(N_{s}\right)$ decreasing. Therefore, if $S\left(N_{s}\right)$ is strictly decreasing over some range, it must have a local maximum. Note that

$$
N_{s} S^{\prime}\left(N_{s}\right)=1-S\left(N_{s}\right)\left(1+N_{s} \frac{e^{\prime}\left(N_{s}\right)}{e\left(N_{s}\right)}\right)
$$

further differentiation yields

$$
S^{\prime}\left(N_{s}\right)+N_{s} S^{\prime \prime}\left(N_{s}\right)=-S^{\prime}\left(N_{s}\right)\left(1+N_{s} \frac{e^{\prime}\left(N_{s}\right)}{e\left(N_{s}\right)}\right)-S\left(N_{s}\right) \frac{d\left(N_{s} \frac{e^{\prime}\left(N_{s}\right)}{e\left(N_{s}\right)}\right)}{d N_{s}}
$$

The necessary condition for a local maximum for $S\left(N_{s}\right)$ then implies $\frac{d\left(N_{s} \frac{e^{\prime}\left(N_{s}\right)}{e\left(N_{s}\right)}\right)}{d N_{s}} \geq 0$, or

$$
\frac{\left(N e^{\prime \prime}\left(N_{s}\right)+e^{\prime}\left(N_{s}\right)\right) e\left(N_{s}\right)-N_{s}\left(e^{\prime}\left(N_{s}\right)\right)^{2}}{\left(e\left(N_{s}\right)\right)^{2}} \geq 0 .
$$

Since the above displayed inequality is violated when (27) holds, we conclude that, if (27) holds, then $S\left(N_{s}\right)$ must be increasing.

The second Lemma relates condition (27) to the hazard rate of the income distribution.

Lemma 4. Condition (27) in Lemma 3 holds if and only if $h(y)$ is increasing.

Proof of Lemma 4. The transformation from the endowment function $e(\cdot)$ to the income function $F(\cdot)$ occurs with the two next displayed equations: for any $N$ such that $e(N)=y \geq e\left(N_{s}^{E Q}\right)$, we have

$$
F(y)=\frac{N_{s}^{E Q}-e^{-1}(y)}{N_{s}^{E Q}}
$$

and

$$
f(y)=-\frac{1}{N_{s}^{E Q} e^{\prime}\left(e^{-1}(y)\right)} .
$$


Moreover, we have

$$
f^{\prime}(y)=\frac{e^{\prime \prime}\left(e^{-1}(y)\right)}{N_{s}^{E Q}\left(e^{\prime}\left(e^{-1}(y)\right)\right)^{3}} .
$$

Now, note that

$$
d \log h(y)=d \log f(y)-d \log (1-F(y))=\frac{f^{\prime}(y)}{f(y)}+\frac{f(y)}{1-F(y)} .
$$

Therefore, $h(\cdot)$ is increasing if and only if

$$
-1<\frac{1-F(y)}{f(y)} \cdot \frac{f^{\prime}(y)}{f(y)}=\frac{\frac{e^{-1}(y)}{N_{s}^{E Q}}}{-\frac{1}{N_{s}^{E Q} e^{\prime}\left(e^{-1}(y)\right)}} \cdot \frac{\frac{e^{\prime \prime}\left(e^{-1}(y)\right)}{N_{s}^{E Q}\left(e^{\prime}\left(e^{-1}(y)\right)\right)^{3}}}{-\frac{1}{N_{s}^{E Q} e^{\prime}\left(e^{-1}(y)\right)}}=N \frac{e^{\prime \prime}(N)}{e^{\prime}(N)} .
$$

But the extremes of the above displayed inequality are nothing but $(27)$, since $e^{\prime}<0$.

The combination of Lemma 3 and 4 establishes the desired result.

Proof of Proposition 5. If $S\left(N_{s}\right)$ is increasing, then taking derivatives we have

$$
\frac{\left(e_{1}\left(N_{s}\right) N_{s}-\int_{0}^{N_{s}} e_{1}(j) d j\right) e_{1}\left(N_{s}\right)-N_{s} e_{1}^{\prime}\left(N_{s}\right) \int_{0}^{N_{s}} e_{1}(j) d j}{N_{s}^{2}\left(e_{1}\left(N_{s}\right)\right)^{2}}>0,
$$

which evaluated at $N_{s}=N_{s}^{E Q}$ yields

$$
\left(e_{1}\left(N_{s}^{E Q}\right) N_{s}^{E Q}-E_{1}\left(N_{s}^{E Q}\right)\right) e_{1}\left(N_{s}^{E Q}\right)-N_{s}^{E Q} e_{1}^{\prime}\left(N_{s}^{E Q}\right) E_{1}\left(N_{s}^{E Q}\right)>0
$$

or

$$
\left(\frac{e\left(N_{s}^{E Q}\right)}{E_{1}\left(N_{s}^{E Q}\right)}-\frac{e^{\prime}\left(N_{s}^{E Q}\right)}{e\left(N_{s}^{E Q}\right)}\right) N_{s}^{E Q}>1
$$

From (24), (25), and (26), with $\frac{\Delta R_{u}}{R_{u}}=\frac{\Delta R_{s}}{R_{s}}$ we obtain

$$
\frac{\frac{\Delta N_{u}^{E Q}}{N_{u}^{E Q}}}{\frac{\Delta N_{s}^{E Q}}{N_{s}^{E Q}}}=N_{s}^{E Q}\left(\frac{e_{1}\left(N_{s}^{E Q}\right)}{E_{1}\left(N_{s}^{E Q}\right)}-\frac{e_{1}^{\prime}\left(N_{s}^{E Q}\right)}{e_{1}\left(N_{s}^{E Q}\right)}\right)
$$

so that, using (28) and recalling that both $\frac{\Delta N_{u}^{E Q}}{N_{u}^{E Q}}$ and $\frac{\Delta N_{s}^{E Q}}{N_{s}^{E Q}}$ are negative,

$$
\left|\frac{\Delta N_{s}^{E Q}}{N_{s}^{E Q}}\right|<\left|\frac{\Delta N_{u}^{E Q}}{N_{u}^{E Q}}\right|
$$


Proof of Proposition 6. Denote the equilibrium populations before the storm as $N_{u}^{B K}$ and $N_{s}^{B K}$, while $N_{u}^{A K}$ and $N_{s}^{A K}$ indicate the equilibrium populations after the storm. Similarly, we use $l_{B K}(x)$ and $l_{A K}(x)$ for the before and after Lorenz curves, whose formal definition is in (23) and immediately above it. From (15), (16), and (18), we have that the ratio of skilled to unskilled market income, $\frac{E_{1}}{P N_{u}}=\frac{E_{1}}{P E_{2}}$, is constant in equilibrium. Therefore, $l_{A K}(x)>l_{B K}(x) \forall x\left[0, \frac{N_{u}^{A K}}{N_{u}^{A K}+N_{s}^{A K}}\right]$, since, by Proposition $4, \frac{N_{u}^{A K}}{N_{u}^{A K}+N_{s}^{A K}}>\frac{N_{u}^{B K}}{N_{u}^{B K}+N_{s}^{B K}} \cdot l_{A K}(x) \geq$ $l_{B K}(x)$ holds. Therefore, if $l_{A K}(x)$ and $l_{B K}(x)$ intersect for $x \in(0,1)$, then they must do so at a point $x^{1}$ where $l_{B K}^{\prime}\left(x^{1}\right) \geq l_{A K}^{\prime}\left(x^{1}\right)$. We now show this is impossible when $S\left(N_{s}\right)$ is increasing. The condition $l_{A K}\left(x^{1}\right)=l_{B K}\left(x^{1}\right)$ implies

$$
\int_{\left(N_{u}^{A K}+N_{s}^{A K}\right)\left(1-x^{1}\right)}^{N_{s}^{A K}} \frac{e_{1}(j)}{\int_{0}^{N_{s}^{A K}} e_{1}(j) d j} d j=\int_{\left(N_{u}^{B K}+N_{s}^{B K}\right)\left(1-x^{1}\right)}^{N_{s}^{B K}} \frac{e_{1}(j)}{\int_{0}^{N_{s}^{B K}} e_{1}(j) d j} d j,
$$

which in turn implies

$$
\frac{\int_{0}^{\left(N_{u}^{A K}+N_{s}^{A K}\right)\left(1-x^{1}\right)} e_{1}(j) d j}{\int_{0}^{N_{s}^{A K}} e_{1}(j) d j}=\frac{\int_{0}^{\left(N_{u}^{B K}+N_{s}^{B K}\right)\left(1-x^{1}\right)} e_{1}(j) d j}{\int_{0}^{N_{s}^{B K}} e_{1}(j) d j} .
$$

Using $S\left(N_{s}\right)$ increasing and $N_{u}^{A K}+N_{s}^{A K}<N_{u}^{B K}+N_{s}^{B K}$, we have

$$
\begin{gathered}
\left(1-x^{1}\right)\left(N_{u}^{B K}+N_{s}^{B K}\right) \frac{e\left(\left(1-x^{1}\right)\left(N_{u}^{B K}+N_{s}^{B K}\right)\right)}{\int_{0}^{\left(N_{u}^{B K}+N_{s}^{B K}\right)\left(1-x^{1}\right)} e_{1}(j) d j} \\
<\left(1-x^{1}\right)\left(N_{u}^{A K}+N_{s}^{A K}\right) \frac{e\left(\left(1-x^{1}\right)\left(N_{u}^{A K}+N_{s}^{A K}\right)\right)}{\int_{0}^{\left(N_{u}^{A K}+N_{s}^{A K}\right)\left(1-x^{1}\right)} e_{1}(j)},
\end{gathered}
$$

which, using (29) implies,

$$
\left(N_{u}^{B K}+N_{s}^{B K}\right) \frac{e\left(\left(1-x^{1}\right)\left(N_{u}^{B K}+N_{s}^{B K}\right)\right)}{\int_{0}^{N_{s}^{B K}} e_{1}(j) d j}<\left(N_{u}^{A K}+N_{s}^{A K}\right) \frac{e\left(\left(1-x^{1}\right)\left(N_{u}^{A K}+N_{s}^{A K}\right)\right)}{\int_{0}^{N_{s}^{A K}\left(1-x^{1}\right)} e_{1}(j) d j},
$$

However, using (23), the above displayed equation directly contradicts $l_{B K}^{\prime}\left(x^{1}\right) \geq l_{A K}^{\prime}\left(x^{1}\right)$.

\section{Acknowledgments}

We thank our colleagues at Tulane University and in particular Nora Lustig for their comments on earlier versions of this paper. 


\section{References}

Albala-Bertrand, J. M. (1993), Natural disaster situations and growth: a macroeconomic model for sudden disaster impacts, World Development 21, 1417-1434.

Anbarci, N., M. Escaleras, C. A. Register (2005), Earthquake fatalities: the interaction of nature and political economy, Journal of Public Economics 89, 1907-1933.

Bagnoli, M. and T. Bergstrom (2005), Log-concave probability and its applications, Economic Theory 26, $445-469$.

Berliant, M., and J. H. Edwards (2004), Efficient allocations in club economies, Journal of Public Economic Theory 6, 43-63.

Bearse, P., G. Glomm, and D. M. Patterson (2005), Endogenous public expenditures on education, Journal of Public Economic Theory 7, 561-577.

Bloomberg (2015), "Visual Data," accessed online August 25, 2015: http://www.bloomberg.com/visualdata/best-and-worst/most-income-inequality-us-cities

Conley, J.P. and H. Konishi (2002), Migration-proof Tiebout equilibrium: existence and asymptotic efficiency, Journal of Public Economics 86, 243-262.

Deryugina, T., L. Kawano, and S. Levitt (2014), The economic impact of Hurricane Katrina on its victims: evidence from individual tax returns, National Bureau of Economic Research Working Paper 20713. Available online at: http://papers.nber.org/tmp/55444-w20713.pdf

De Silva, D. G., R. P. McComb, Y. Moh, A. R. Schiller, and A. J. Vargas (2010), The effect of migration on wages: evidence from a natural experiment, American Economic Review: Papers \& Proceedings 100, $321-326$.

Fussell E., N. Sastry, and M. van Landingham (2010), Race, socioeconomic status, and return migration to New Orleans after Hurricane Katrina, Population and Environment 31, 20-42.

Geagham, K. A. (2011), Forced to move: an analysis of Hurricane Katrina movers 2009 American Housing Survey: New Orleans, U.S. Census Bureau SEHSD Working Paper \#2011-17

GNO (2013), Greater New Orleans urban water plan, available at http://livingwithwater.com/blog/urban_water_plan/reports 
Gradstein, M. and M. Justman (1996), The political economy of mixed and private schooling: a dynamic analysis, International Tax and Public Finance 3, 297-310.

Groen, J. A. and A. E. Polivka (2008), The effect of Hurricane Katrina on the labor market outcomes of evacuees, American Economic Review 98, 43-48.

Groen, J. A. and A. E. Polivka (2010), Going home after Hurricane Katrina: determinants of return migration in affected areas, Demography 47, 821-844.

Huffington Post (2015), 5 Post-Katrina innovations New Orleans can brag about, Aug. 29, 2015, http://www.huffingtonpost.com/sierra-club/5-postkatrina-innovations_b_8056790.html

Jabbar, Huriya (2015a), How do school leaders respond to competition? Education Research Alliance for New Orleans, Policy Brief, March 2015.

Jabbar, Huriya (2015b), How do school leaders respond to competition? Education Research Alliance for New Orleans, Technical Report, March 26, 2015.

Louisiana Department of Education (2006), Public school openings scheduled for Spring 2006 in Orleans parish, http://www.louisianaschools.net/lde/uploads/8471.pdf, accessed February 15, 2006.

Louisiana Tax Commission (2003), Thirty-first biennial report, 2002-2003, available at http://www.latax.state.la.us/Menu_AnnualReports/AnnualReports.aspx

Louisiana Tax Commission (2005), Thirty-second biennial report, 2004-2005, available at http://www.latax.state.la.us/Menu_AnnualReports/AnnualReports.aspx

Louisiana Tax Commission (2007), Thirty-third biennial report, 2006-2007, available at http://www.latax.state.la.us/Menu_AnnualReports/AnnualReports.aspx

Louisiana Tax Commission (2008), Annual report, 2008, available at http://www.latax.state.la.us/Menu_AnnualReports/AnnualReports.aspx

Louisiana Tax Commission (2014), Annual report, 2014, available at http://www.latax.state.la.us/Menu_AnnualReports/AnnualReports.aspx

McIntosh, M. F. (2008), Measuring the labor market impacts of Hurricane Katrina migration: evidence from Houston, Texas, American Economic Review 98, 54-57.

Plyer, A. and V. Mack (2015), Neighborhood recovery rates growth continues through 2015 in New Orleans neighborhoods, The Data Center, available at https://s3.amazonaws.com/gnocdc/reports/TheDataCenter_NeighborhoodRecovery2015.pdf 
Ruggles, S., J. Trent Alexander, Katie Genadek, Ronald Goeken, Matthew B. Schroeder, and Matthew Sobek. Integrated Public Use Microdata Series: Version 5.0 [Machine-readable database]. Minneapolis, MN: Minnesota Population Center [producer and distributor], 2010.

Scotchmer, S. (2002), Local public goods and clubs, in the Handbook of Public Economics Vol 4, A. Auerbach and M. Feldstein, eds., North Holland Press, 1997-2042.

Sebelius, K. (2015), How post-Katrina New Orleans transformed its health care system, The Boston Globe, Aug. 28, 2015, available at https://www.bostonglobe.com/opinion/2015/08/28/how-post-katrina-new-orleans-transformed-its-healthcare-system/5yoAmcLDa2OSSjM405tW0J/story.html

Shaughnessy, T. M., M. L. White, and M. D. Brendler (2010), The income distribution effect of natural disasters: an analysis of Hurricane Katrina, The Journal of Regional Analysis and Policy 40, 84-95.

Shrinath, N. and A. Plyer (2015), New Orleans: the hub of water management innovation?, Stanford Social Innovation Review, August, 2015.

The Data Center (2015a) http://www.datacenterresearch.org/data-resources/population-by-parish and http://www.datacen resources/who-lives-in-new-orleans-now, consulted June 17, 2015.

The Data Center (2015b) Neighborhood recovery rates: growth in New Orleans neighborhoods continues in 2015, available at http://www.datacenterresearch.org/reports_analysis.

U.S. Census Bureau (2008), Special population estimates for impacted counties in the gulf coast area, available at https://www.census.gov/newsroom/emergencies/additional/impacted_gulf_estimates.html, consulted June 10, 2015.

U.S. Census Bureau (2015), American Fact Finder, available at Factfinder.census.gov/faces/tableservices/jsf/pages/productview.xhtml?src=bmk, accessed June 20, 2015. 